PESHAWAR JOURNAL OF PSYCHOLOGY AND BEHAVIORAL SCIENCES, 2016, VOL. 2, NO. 2, 235-247

\title{
Relationship Between Authentic Leadership, Work Engagement and Job Stress among Employees of Telecommunication Organizations
}

\author{
Fatoom Dar' ${ }^{1}$ Imran Bukhari ${ }^{2}$ and Mahak Hamid ${ }^{3}$ \\ Quaid-e-Azam University Islamabad
}

The present study aimed to study the relationship between the perception of authentic leadership, work engagement and job stress among the employees of telecommunication sector in the Rawalpindi/ Islamabad region of Pakistan. The sample consisted of 200 employees taken from different telecommunication sectors from Rawalpindi/ Islamabad, ranging between ages 2260. Authentic leadership questionnaire by Walumbwa Wang, Wang, \& Schaubroeck (2010) to measure authentic leadership, work engagement scale by Schaufeli, Salanova, Gonzalez-Roma, and Bakker (2001) to measure employee engagement at work and job stress scale by Parker and De-Cotiis (1983) to measure job stress was used. The results of the present study showed that significant positive correlation exist between authentic leadership, work engagement $\left(.49^{* *}\right)$ and its dimensions vigor $\left(.36^{* *}\right)$, dedication $(.39 * *)$, and absorption (.53). In the present study results of regression analysis showed that authentic leadership was the significant predictor of work engagement and its dimensions. While no significant. relation was found between authentic leadership and job stress, as well as job stress and work engagement. Male employees rated themselves high on selfassessment questionnaire of authentic leadership. Women rated themselves higher on job stress while men rated themselves higher on work engagement. No significant age, experience, income or educational differences were found.

Keywords: authentic leadership, work engagement, job stress, employees and telecommunication sector.

\footnotetext{
${ }^{1}$ Student at National Institute of Psychology, Quaid-e-Azam University, Islamabad

${ }^{2}$ Lecturer atNational Institute of Psychology, Quaid-e-Azam University, Islamabad

${ }^{3}$ Student at National Institute of Psychology, Quaid-e-Azam University Islamabad
} 
Throughout the history leadership has known to produce remarkable effects in human life. Leadership has known to make organizations successful but unhealthy leadership can devastate the infrastructure of the organizations. Now a days the individuals and employees are the main focus of the organizations. Organizations tend to keep their employees happy and motivated because they have realized the need that employees are the main assets. Loyal and faithful employees can give the organizations competitive edge over the others. Pakistani organizations were known to adapt bureaucratic structures which were governed by autocratic style of leadership. But, now the organizational structure is tilted towards decentralization and the authority holders tries to adapt authentic leadership. Authentic leadership is a type of leadership that emphasize to build relationships on honest and ethical foundations; It mostly depends on the legitimacy of the leader (Gardner, Cogliser, Davis, \& Dickens, 2011). Authentic leaders are reliable and moderate and their leadership makes a personal growth in them.(George, 2003). Authentic leadership is a newly developed construct, and it has played important role in growing theoretical and empirical researches (Gardner et al., 2011). Work engagement is described as a persistent, positive, affective-cognitive state of fulfilment in employees (Schaufeli, Martinez, Pinto, Salanova \& Bakker, 2002). Research has revealed that engaged employees are highly energetic, selfefficacious individuals (Bakker, 2009). In terms of obligation, acknowledgment and achievement, the engaged employees are able to develop their own constructive response due to having optimistic approach and activity level. Beside the fact that engaged employee do have feeling of fatigue after a long hard working schedule, they take this feeling as an amusing state as it is related with positive achievement. Lastly, engaged employees have also meaning of taking a good time outside the working hours. Engaged employees work hard because working hard is a fun for them not due to having a strong and desirable inner motivation like workaholics. (Gorgievski, Bakker \& Schaufeli, 2010). HSE's (2012) formal definition of work related stress is, "The adverse reaction people have to excessive pressures or other types of demand placed on them at work."

Relationship between authentic leadership, work engagement and job stress in literature suggests strong empirical evidence between authentic leadership, work engagement and job stress. Hassan and Ahmad (2011) has concluded that authentic leadership can produce 
effects of trust which in turn increases the level of work engagement in the employees. Moreover it has been seen throughout the literature that the positive attitude positively correlates with the work performance in the employees. Leader's positive attitude creates the feelings of trust. Caponetti (2012) had also concluded that when employees are satisfied with their supervisors then this satisfaction plays a mediating role between stress and work engagement. Relationships with supervisor can also act as a buffer between employee engagement and stress (Bakker \& Demerouti, 2007).

Research has indicate positive relationships between authentic leadership and positive job outcomes such as high job performance (Clapp-Smith, Vogelgesang, \& Avey, 2009), organizational citizenship behaviour(Carsten, Crossley, \&Avolio, 2008), psychological empowerment, trust in management and work engagement (Carsten et al. 2008, Walumbwa, Wang, Wang, \& Schaubroeck, 2010)

Previous studies have also shown significant negative relationship between work engagement and job stress. Hakanen, Bakker, \& Schaufeli, 2006 conducted a study which showed that when employees are hard working, motivated, energetic, and are highly engaged with their job then their job stress decreases. Their study correlated with the study of Koyuncu, Burke, \& Fiksenbaum, 2006). J D$\mathrm{R}$ model has also found that there is significantly negative relationship between as job demands and work engagement (Bakker \& Demerouti, 2007).

Work engagement is a fulfilling positive experience for the employees and it greatly impacts the physical and psychological health of employees and vice versa. When the employees are relaxed and in good mental state then they will be more engaged with their jobs. Throughout the research it has been seen that stress negatively affects the physical and mental health of the individuals. It produces the feelings of hypertension, irritability, and anxiety which in turns stagnate the working of the mind. Such individuals cannot concentrate on their work and show the symptoms of low work engagement (Cartwright \& Cooper 2002; Martin 2005; Schaufeli \& Bakker, 2004; Sonnentag, Mojza, Demerouti \& Bakker, 2012).

The employees who reported high levels of work stress had showed negative job outcomes such as low job performance, low selfesteem, inability to concentrate, short attention span, burnout and job dissatisfaction. Research has also indicated a positive relationship 
between stress and absenteeism and between stress and labor turnover (Coetzer \& Rothmann 2007; Mostert, Rothmann, Mostert, \& Nell, 2008). Coetzer and Rothmann (2007) also concluded that relationship with superiors, social support and opportunities are positively related to work engagement. Lee, Hourquet and MacDermid (2002) had showed that the reduced workload decreases the level of stress in the employees and in turn enhances employee creativity. Higher levels of employee engagement have also shown to decrease the level of stress in employees because such employees perceive their job as a challenge and become more motivated by tough jobs (Hakanen et al., 2006).

Coetzee and Villers (2010) have observed significant differences between male and female participants with regard to the work engagement variables of total engagement, dedication and absorption.

\section{Rationale}

In Pakistani context, the phenomenon of authentic leadership has not been studied in detail. Authentic leadership has been known to decrease job stress and this information can provide a solid basis for devising strategies to reduce stress at work, thereby leading to work engagement and increased productivity.

Previous literature in Pakistani context has laid emphasis on job stress and its effect but the reasons which are inducing stress has not been explored. The present study was an attempt to explore leadership as the main reason of producing job stress in the employees of telecommunication sector.

Telecommunication sector in Pakistan has decentralized and modern organizational structures. As telecommunication is under the influence of multinational companies; hence, authentic leadership is very commonly observed in this sector. So telecommunication sector is targeted in this research project to study the current variables.

The effect of leadership on gender is also studied in this research because men and women perceive leadership differently. Male employees can perceive their boss as friendly and will be motivated by authentic leadership while the same type of behaviour can be perceived negatively in our context.

The major objectives of the present study were to explore the relationship between authentic leadership, job stress and work engagement among employees of telecommunication organizations. It was also intended to explore demographics variable (such as gender, 
work experience, educational differences, and income differences) in relation to study variables.

\section{Objectives}

- To find the relationship between authentic leadership and work engagement among employees of telecommunication organizations.

- To Study the relationship between authentic leadership and job stress among employees of telecommunication organizations

\section{Hypotheses}

The following hypotheses were formulated in accordance to the literature:

- There shall be a positive relationship between authentic leadership and work engagement among employees of telecommunication organizations.

- There shall be a negative relationship between authentic leadership and job stress among employees of telecommunication organizations

\section{$\bullet$}

\section{Method}

\section{Sample}

The sample was comprised of 200 employees of telecommunication sector in the Rawalpindi/Islamabad region. Their educational level ranged from bachelors to master's level and their ages varied from 22-60 years old. Telecommunication sector i.e., Ufone, Waird, Zong, Mobilink, Telenor, Ibex and Nayatel were visited for the data collection.

\section{Measures.}

\section{Authentic leadership Questionnaire}

This self-assessment questionnaire is designed by Walumbwa et al. (2010) to measure the authentic leadership by assessing four components of the process: self-awareness, internalized moral perspective, balanced processing, and relational transparency. Authentic leadership score (the total score) can be interpreted by using the 
following guidelines: very high $=64-80$, high $=48-64$, low $=32-48$, and very low $=16-32$. Scores in the upper ranges indicate stronger authentic leadership, whereas scores in the lower ranges indicate weaker authentic leadership. ALQ is validated by Sierpinska (2013) and reliability of this questionnaire is .80 . Alpha reliabilities in this research for the current scale was found to be .70 .

\section{Work Engagement Scale}

Work engagement was measured using the Utrecht Work Engagement Scale developed by Schaufeli, Salanova, Gonzalez-Roma, and Bakker (2003). The scale three subscales such as vigor, dedication and absorption. It is consisted of nine items ( 3 items for each subscale). The tool uses a 7 point Likert Type scale where $0=$ Never and $7=$ Always. The reliability of this scale is .90 . The Aplha reliability of work engagement scale in this research was found to be .88 . The reliabilities of the subscale were found to be Vigor $=.83$, Dedication $=.83$, and Absorption $=.62$.

\section{Job stress scale}

Job stress was measured using Job stress scale developed by Parker and De Cotiis (1983). It consists of 13 items. . Responses to items were rated at 5-point Likert scale such as $1=$ strongly disagree, $2=$ disagree, $3=$ neutral, $4=$ agree, and $5=$ strongly agree. Higher score on this scale indicates a higher degree of job stress. The Cronbach alpha reliability for this scale was found to be 0.85 (Jamal \& Baba, 2000). Alpha reliability of Job stress scale in this research was found to be 69 .

\section{Procedure}

First of all the authority of the organization were contacted for data collection. Printed questionnaires were handed to the employees and their supervisors. The respondents were briefed about the purpose of the research. The rating process for each questionnaire was explained. Employees were given declaration about the confidentiality of their responses. 275 questionnaires were disseminated in the organizations out of which 75 were discarded and 200 were used for analysis. 


\section{Results}

Inter scale correlation were computed to see the relationship between variables of the study. Mean was also computed for all the scales of the study. Linear regression was used to determine the effect of age, experience and Authentic leadership on the study variables. t-test was computed to determine the educational differences in authentic leadership, job stress, work engagement, vigour, dedication and absorption. One way ANOVA was applied to establish the differences on the basis of income.

\section{Correlation Analysis}

Table 1

Inter Scale Correlations Among Study Variables $(N=200)$

\begin{tabular}{lllccccc}
\hline & Scales & 1 & 2 & 3 & 4 & 5 & 6 \\
\hline 1 & Al & - & $.22^{*}$ & $.49^{* *}$ & $.36^{* *}$ & $.39^{* *}$ & $.53^{* *}$ \\
2 & JS & & & .03 & .08 & .01 & .02 \\
3 & WE & & & & $.89^{* *}$ & $.92^{* *}$ & $.82^{* *}$ \\
4 & Vigour & & & & & $.77^{* *}$ & $.57^{* *}$ \\
5 & Dedication & & & & & $.62^{* *}$ \\
6 & Absorption \\
Note: & ${ }^{*}$ Al = Authentic Leadership; JS $=$ \\
$<0.01$ & Job Stress; WE = Work Engagement; ${ }^{* * p}$
\end{tabular}

Table 1 shows the values of Pearson product Moment Correlation among variables of the study. Perception of authentic leadership has significant positive relationship with work engagement that is $.496^{* *}$ and its dimensions vigor, dedication and absorption, $\left(.36^{* *}, .39^{* *} \& .58^{* *}\right)$ where as it has no significant relationship with job stress (.22). Perception of job stress has non-significant relationship with Work engagement and its dimensions (vigor, dedication and absorption). 
Table 2

Linear Regression Analysis

Note: $\mathrm{AL}=$ Authentic Leadership, $\mathrm{WE}=$ Work Engagement, $* * \mathrm{p}<.01$

\begin{tabular}{|c|c|c|c|c|}
\hline & \multicolumn{4}{|c|}{ Authentic leadership } \\
\hline & \multicolumn{4}{|c|}{ Model } \\
\hline & & & \multicolumn{2}{|c|}{$95 \% \mathrm{CI}$} \\
\hline Variables & $B$ & S.E & $L L$ & $U L$ \\
\hline Constant & 7.06 & & -11.11 & 25.23 \\
\hline WE & .68 & 7.06 & .37 & .99 \\
\hline $\mathrm{R}^{2}$ & .25 & & & \\
\hline $\mathrm{F}$ & $19.54 * * *$ & & & \\
\hline Constant & 4.16 & & -3.22 & 11.53 \\
\hline Vigor & .19 & 2.87 & .064 & .31 \\
\hline $\mathrm{R}^{2}$ & .13 & & & \\
\hline $\mathrm{F}$ & $9.17 * *$ & & & \\
\hline Constant & 3.78 & & -3.98 & 11.55 \\
\hline Dedication & .21 & 3.02 & .08 & .35 \\
\hline $\mathrm{R}^{2}$ & .15 & & & \\
\hline $\mathrm{F}$ & $10.66 * *$ & & & \\
\hline Constant & -.88 & & -7.64 & 5.88 \\
\hline Absorption & .28 & 2.63 & .16 & .39 \\
\hline $\mathrm{R}^{2}$ & .28 & & & \\
\hline $\mathrm{F}$ & $23.24 * *$ & & & \\
\hline
\end{tabular}

Table 2 suggests that authentic leadership significantly predict work engagement $\{\mathrm{R} 2=.25, \mathrm{~F}=19.54, \mathrm{p}=.001\}$ in positive direction. It also predict vigor $\{\mathrm{R} 2=.13, \mathrm{~F}=9.17, \mathrm{p}=.01\}$ in positive direction and dedication $\{\mathrm{R} 2=.15, \mathrm{~F}=10.66, \mathrm{p}=.01\}$, where as it predict absorption in negative direction $\{\mathrm{R} 2=.28, \mathrm{~F}=23.24, \mathrm{p}=.01\}$. 


\section{Discussion}

The aim of this research was to explore the relationship between authentic leadership, Work engagement and Job stress among employees of telecommunication sector. Authentic leadership is a phenomenon in which leader works with purpose, values, integrity and enthusiasm. Engagement is a process in which an employee has work related state of mind, where as the third variable which is job stress, basically means having disproportionate pressure. This research is a correlational research. The present study was aimed at exploring the effect of authentic leadership on job stress and make employees engaged in their work.

The first hypothesis of this research was that authentic leadership shall be negatively related with job stress. The results of the present study showed that there is non-significant relationship between authentic leadership and job stress. The findings of my research are same as Avolio's (2005) research on authentic leadership, job satisfaction, role stress / job stress and work engagement. Avolio's (2005) research showed that authentic leadership has non-significant relationship with job stress. These results can be due to two different sources, through which data was collected. Authentic leadership questionnaires were filled by the supervisors whereas job stress questionnaire were filled by the employees of telecommunication sector.

The second hypothesis of this research was that there shall be a positive relation between authentic leadership and work engagement. The results of this study showed a significant positive relation between authentic leadership and work engagement, as well as with the three dimensions of work engagement respectively. The study of (Gardner et al, 2005; Walumbwa et al, 2010) supports the result of present research. These findings were also supported by the research conducted by Hassan and Ahmad (2011). The logic behind these results is that when the leader is applying the authenticity, employees working under him shall be engaged because they get the guidelines of their leaders and employees will identify with their leader and in response they will be more involved in their work. Supervisors' consistency between words and actions as well as their moral perceptions are positively related to employee engagement (Wang \& Hsieh, 2013).

The second hypothesis of this research further suggested that job stress shall be negatively related with work engagement. But the results of the present study showed a non-significant relation between job stress 
and work engagement. The absence of a statistically significant relationship between job stress (because of job demands) and work engagement (vigor and dedication) is in line with the findings of Jackson, Rothmann and Vijver (2006) and Schaufeli and Bakker (2004) which showed a non-significant relation between job stress and work engagement. The cause of getting these results can be a company's positive behaviour toward its employees. The employees who receive attractive pays and profits from the organization are more engaged in their work, that makes them more satisfied with their work, and those benefits make them more enthusiastic and keep them away from any kind of job stress.

Regression analysis was carried out to estimate the predictive role of authentic leadership on work engagement and its dimensions (See table 2). The results of regression analysis showed that authentic leadership was significant predictor of work engagement and its dimensions. These results are same as found in the research of Liu and Yan (2012). They found that authentic leadership can be used to predict employee's psychological safety, work engagement, positive employee health, knowledge sharing and work deviance behaviour. Authentic leadership increase employee job satisfaction which is the predictor that job satisfaction will make employees more engaged in their work (Lisa, Carol \& Carrol, 2010). Increased employee engagement in work results in better employee productivity and loyalty, and engagement can be improved by using more positive supervisory communication styles and leadership styles (Attridge, 2009).

Thus the present study reveals that there is a positive relationship between authentic leadership, work engagement and its dimensions. Whereas there is non-significant relation between authentic leadership and job stress, as well as job stress and work engagement has nonsignificant relation with each other. The findings of the research might be due to the conductive environment of the telecommunication sector that might enhance work engagement, authentic leadership and might condense job stress with the passage of time.

\section{Limitations and Suggestions}

The present study inherited a few possible limitations and suggestions: 1. The sample of this research was small and the majority was male. 
2. Sample was only composed of the telecommunication sectors of Islamabad and Rawalpindi, and we cannot generalize the study findings on to the population of Pakistan which have exclusively different setting and environment.

3. The study includes convenient sample, including only employees of telecommunication sector.

4. The data was collected from two sources (employees / supervisors) and this can be a cause of getting non-significant results between variables of the study.

5. The data of authentic leadership is collected through the self-report measure, it is likelihood that employees might have veiled their true responses and biasness may have occurred.

6. Size of the sample should be increased to well represent the population.

7. Future research should try to use same source/sample for the questionnaires to get filled.

8. Future research is needed to explore whether the non-significant relationship observed in the present study are due to the unique aspects of the context.

9. Future studies may test the relationship of these variables from different types of organizations and industries.

10. Both employees and supervisors related measures should be used in future to lessen the biasness.

\section{Conclusion}

The study was conducted on the telecommunication sector employees to find out the relationship between authentic leadership, work engagement and job stress. This research found a significantly positive relation between authentic leadership and work engagement, whereas it found a non-significant relation between authentic leadership and job stress. Various demographic variables were also studied. The results also showed that education and income had non-significant relation with authentic leadership, work engagement and job stress. According to the gender differences, results showed that male are more engaged in work engagement and perceiving authentic leadership, whereas female face more job stress than males. 


\section{Implications}

Current research can provide a useful insight on leadership and its effect on job outcomes. It provides the empirical evidence that authentic leadership can be used as a asset to reduce job stress and increase work engagement in the employees. Pakistani organizations can gain competitive edge by implementing authentic style of leadership in their infrastructure. Current study also provides knowledge that women employees are more prone to job stress which can stagnate their growth and working. Hence, if their bosses use the correct type of leadership then they can help to enhance the productive behavior.

\section{References}

Avolio, Bruce J. and William L. Gardner. "Authentic leadership development: Getting to the root of positive forms of leadership." The Leadership Quarterly 16, no. 2 (2005): 315-338.

Bakker, Arnold. and Wilmar Schaufeli. "Positive organizational behavior: Engaged employees in flourishing organizations." Journal of organizational behavior 29, no. 2 (2008): 147-154.

Bakker, B. Arnold., Jari. J. Hakanen, Evangelia Demerouti, and Despoina Xanthopoulou."Job resources boost work engagement, particularly when job demands are high." Journal of Educational Psychology 99, no. 2 (2007): 274-284.

Banihani, Muntaha., Patricia Lewis and Jawad Syed."Is work engagement gendered? Gender in Management." An International Journal 28, no.7 (2013): 400- 423.

Caponetti, Amy, Rebecca. "The correlates of work role stress with employee burnout, engagement." $\mathrm{PhD}$ dissertion, University of Tennessee, Knoxville, 2012.

Clapp-Smith, Rachel, Gretchen Vogelgesang and James Avey. "Authentic leadership and positive psychological capital: The mediating role of trust at the group level of analysis." Journal of Leadership and Organizational Studies 15, no. 3 (2009): 227240.

Coralia, Sulea, Virga Delia, Laurentiu P. Maricutoiu, Schaufeli Wilmar, Catalina Zaborila Dumitru, and Florin A. Sava. "Work engagement as mediator between job characteristics and positive 
and negative extra-role behaviors." Career Development International 17, no.13 (2012): 187-207.

Hassan, Arifand Forbis Ahmed. "Authentic leadership, trust and work engagement." World Academy of Science, Engineering and Technology 80, no. 8 (2011): 750-756.

Jackson, Leon, T. B., Sebastiaan Rothmann and Van De Vijver. “A model of work-related wellbeing for educators in south Africa." Stress and health 22, no.4 (2006): 263-274.

Kong, Ying. "A study on the job engagement of company employees." International Journal of Psychological Studies 1, no.2 (2009): $65-68$

Liu, Yan. "Linking authentic leadership to positive employee health, behavioral engagement, and job performance." Mphil thesis, Interdisciplinary in occupational health and management. Lausiana tech University, United States, 2012.

Schaufeli, Wilmar and Arnold Bakker. "Job demands, job resources, and their relationship with burnout and engagement: A multi-sample study." Journal of Organizational Behavior 25, (2004): 293-315.

Walumbwa, O, Fred, Peng Wang, Hui Wang, John Schaubroeck, and Bruce J. Avolio. "Psychological processes linking authentic leadership to follower behaviors. The Leadership Quarterly 21, no.5 (2010): 901-914.

William L. Gardner T, Bruce J. Avolio, Fred Luthans, Douglas R. May, and Fred Walumbwa. "Can you see the real me? A self-based model of authentic leader and follower development." The Leadership Quarterly 16, (2005): 343-372. 